\title{
Association of gut inflammation with increased serum IgA class Klebsiella antibody concentrations in patients with axial ankylosing spondylitis (AS): implication for different aetiopathogenetic mechanisms for axial and peripheral AS?
}

\author{
Outi Mäki-Ikola, Marjatta Leirisalo-Repo, Ulla Turunen, Kaisa Granfors
}

\begin{abstract}
Objectives-A role for Klebsiella pneumoniae in ankylosing spondylitis (AS) has been suggested because faecal carriage of Klebsiella and serum Klebsiella specific antibodies may be increased in this disease. This study has extended the earlier findings by comparing Klebsiella specific serum IgA class antibodies with inflammatory changes in the gut.

Methods-IgA antibodies to $K$ pneumoniae, Escherichia coli, and Proteus mirabilis in serum samples of 25 patients with AS, of eight control patients, and of 100 healthy blood donors were measured by enzyme immunoassay. Gut inflammation of the patients was studied by ileocolonoscopy.

Results-Increased IgA antibody concentrations to $K$ pneumoniae associated with gut inflammation in patients with axial form of AS. Such association was not seen in patients with peripheral form of AS. Conclusions-These findings may provide further evidence for the role of $K$ pneumoniae in the pathogenesis of AS. However, at least some of the patients with axial AS without gut inflammation, as well as patients with peripheral AS did not have increased $K$ pneumoniae antibody concentrations, which may be regarded as evidence against the direct role of $K$ pneumoniae in the pathogenesis. The aetiopathogenetic mechanisms in the axial and peripheral form of AS may be different.
\end{abstract}

(Ann Rheum Dis 1997;56:180-183)

The aetiology of ankylosing spondylitis (AS) is still unknown but the Gram negative microorganism Klebsiella pneumoniae has been suggested to play an important part in the pathogenesis, ${ }^{1-4}$ although this association between Klebsiella and AS is still a subject of controversy. ${ }^{5}$ A high frequency of inflammatory changes ${ }^{67}$ and increased permeability of the gut, ${ }^{8}$ as well as high serum concentrations of total $\operatorname{IgA}$ and secretory $\operatorname{IgA}$ support the role of gut and mucosal immune defence mechanisms. Furthermore, AS can be divided into two forms: (a) patients who have pure axial form of the disease and (b) patients with not only axial, but also peripheral joint arthritides. There have been suggestions for different aetiopathogenetic mechanisms for these two forms. ${ }^{3}$ For example, ileocolonoscopic differences have been reported between patients with axial and peripheral form of AS. ${ }^{67}$ In addition, sulphasalazine, a drug used to treat inflammatory bowel disease, seems to be especially effective in patients with the peripheral type of AS. ${ }^{9}$ We have extended the earlier findings by comparing Klebsiella specific serum IgA class antibodies with inflammatory changes in the gut in patients with axial and peripheral types of AS.

\section{Methods}

Twenty five patients with AS (only axial form, 14; also peripheral arthritides, 11; with mean (SD) duration of disease 7.1 (4.9) and 6.3 (5.3) years, respectively) and, as controls, eight patients with miscellaneous rheumatic diseases (rheumatoid arthritis, 3; low back pain, 3; fibromyalgia, 1; psoriatic arthritis, 1), and 100 healthy blood donors were studied. ${ }^{6}$ In patients with axial and peripheral AS the mean (range) erythrocyte sedimentation rates (ESR) were 36 (5-80) and $47(6-86) \mathrm{mm} / \mathrm{h}$, respectively; the corresponding figures for $\mathrm{C}$ reactive protein (CRP) were 27 (0-103) and 41 (0-160). The ESR and CRP values for control patients were 39 (2-88) and 18 (2-57). Of the AS patients all 23 tested were HLA-B27 positive; of the control patients three were HLA-B27 positive. Eleven $(79 \%)$ of the patients with axial AS, nine $(82 \%)$ of the patients with peripheral AS, and six $(75 \%)$ of the control patients received non-steroidal anti-inflammatory drugs within one month before the ileocolonoscopy. Ileocolonoscopies were performed for patients as described earlier ${ }^{6}$ for a clinical indication of silent gut inflammation. Patients with previously diagnosed inflammatory bowel disease or with chronic diarrhoea were excluded from the study. Of the AS patients, eight were identified as having inflammation in ileum (four patients with axial and four with peripheral form of AS), nine in colon (three with axial and six with peripheral form of AS), and 14 in ileum or in colon (six with axial and eight with peripheral form of AS). Thirteen 


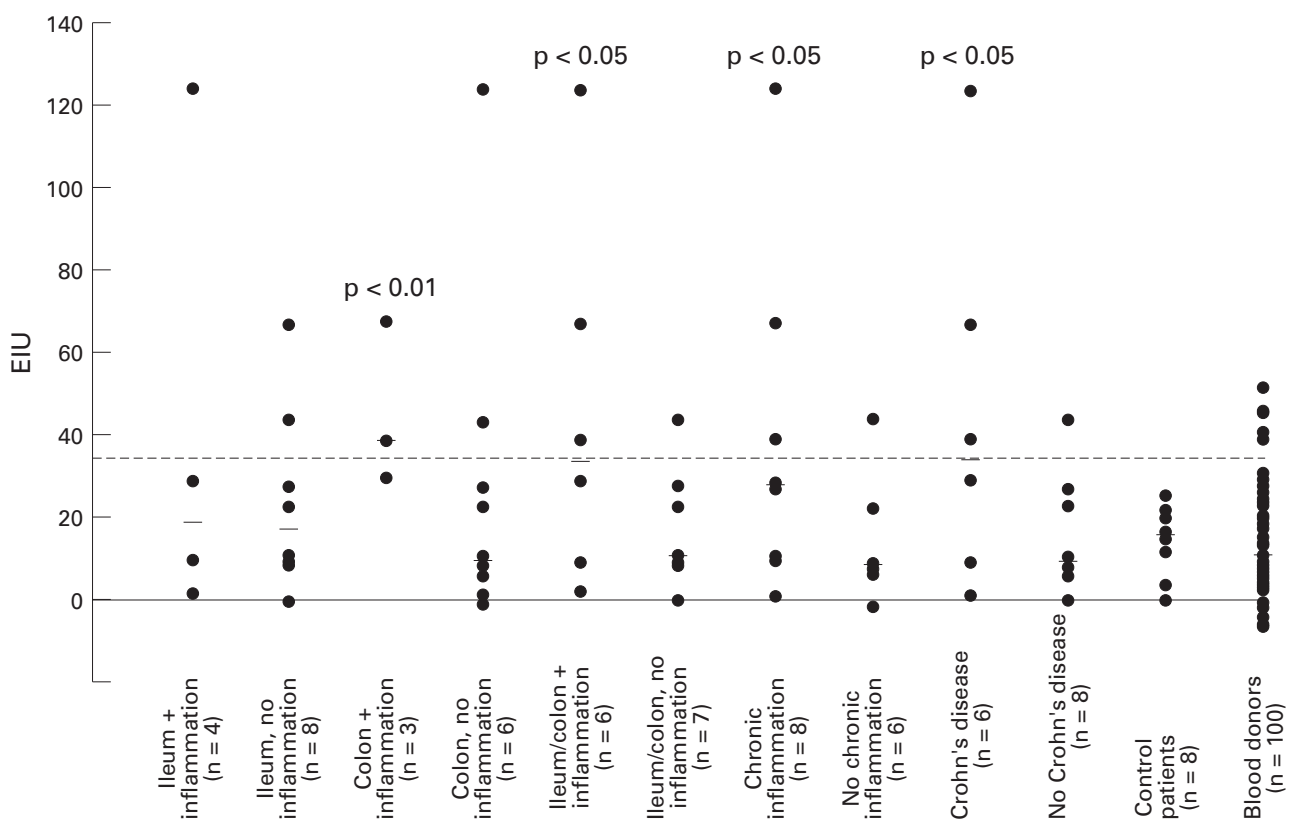

Figure 1 IgA class antibody concentrations to Klebsiella pneumoniae in serum samples of patients with axial type of ankylosing spondylitis, grouped according to ileocolonoscopic findings. Results for the control patients with other rheumatic diseases and healthy controls are also shown. $p$ Values are given when compared with the healthy controls. The dashed line shows the antibody value for mean (2SD) of the healthy blood donors. EIU, enzyme immunoassay unit. Median values for each subgroup have been marked with horizontal lines.

patients (eight with axial and five with peripheral form of AS) were identified as having chronic inflammation in the gut. Ten patients (six with axial form and four with peripheral form of AS) had possible or definite Crohn's disease. $^{6}$ In control patients with other rheumatic diseases the endoscopic findings were normal, except for one patient with mild inflammation in colon. IgA class serum antibodies against $K$ pneumoniae, Escherichia coli, and Proteus mirabilis were measured by enzyme immunoassay (EIA) as described earlier. $^{23}$ Briefly, the polystyrene microtitre plates (Nunc, Roskilde, Denmark) were coated with sodium dodecyl sulphate extracts of the bacteria in phosphate buffered saline (PBS) overnight at $37^{\circ} \mathrm{C}$. The plates were saturated with $1 \%$ normal sheep serum in PBS (NSS-PBS). Patient serum samples at 1:250 dilution were incubated on the plates for two hours at $37^{\circ} \mathrm{C}$. Thereafter, alkaline phosphatase conjugated swine antihuman IgA (Orion Diagnostica, Espoo, Finland), diluted $1: 250$, was incubated on the plates overnight at room temperature. Fresh $p$-nitrophenyl phosphate in diethanolamine- $\mathrm{MgCl}_{2}$-buffer solution ( $1 \mathrm{mg} / \mathrm{ml}$; Orion Diagnostica) was added, incubated for 30 minutes at $37^{\circ} \mathrm{C}$, and the reaction stopped with $1 \mathrm{M}$ sodium hydroxide. The optical density was measured with a Titertek Multiscan Photometer (Labsystems, Helsinki, Finland) at a wavelength of $405 \mathrm{~nm}$. Antibody concentrations were expressed as enzyme immunoassay units (EIU): 1 EIU is $1 / 100$ of the corresponding antibody concentration in the positive reference serum.

The median concentrations of antibodies in different groups were compared with the Mann-Whitney test.

\section{Results}

Similar to earlier findings ${ }^{1-4}$ the AS patients had higher IgA class serum antibody concentrations against $K$ pneumoniae when compared with the healthy controls (mean (SD) EIU: 20.9 (27.0) and 12.3 (11.4), respectively; $\mathrm{p}<0.05)$. When the patients were grouped as having either axial or peripheral type of AS, this increase was seen only in patients with axial type of the disease (28.7 (33.2); $\mathrm{p}<0.001)$. No statistically significant increases were seen in the IgA antibody values against $E$ coli or $P$ mirabilis in the AS patients.

When K pneumoniae specific serum antibody concentrations were analysed in relation to ileocolonoscopic findings, the patients with axial AS and gut inflammation always had higher average Klebsiella specific IgA class antibody values when compared with the patients without these gut lesions and with the control groups (fig 1). When the Klebsiella antibody concentrations were analysed in patients with peripheral form of AS, no clear picture emerged (fig 2). The Klebsiella antibody values were sometimes even higher (not statistically significant) in patients without a gut inflammation when compared with those with that same type of gut inflammation.

The association between the increased Klebsiella specific IgA class antibody concentrations and gut inflammation in AS patients with pure axial form of the disease seemed to be specific for K pneumoniae, as no such increases were seen in the $P$ mirabilis specific antibody concentrations in patients with gut lesions, and only patients with inflammation in colon had increased antibody concentration to $E$ coli $(\mathrm{p}<0.05)$ when compared with the blood donors.

Interestingly, the patients with peripheral type of AS and inflammation in ileum 


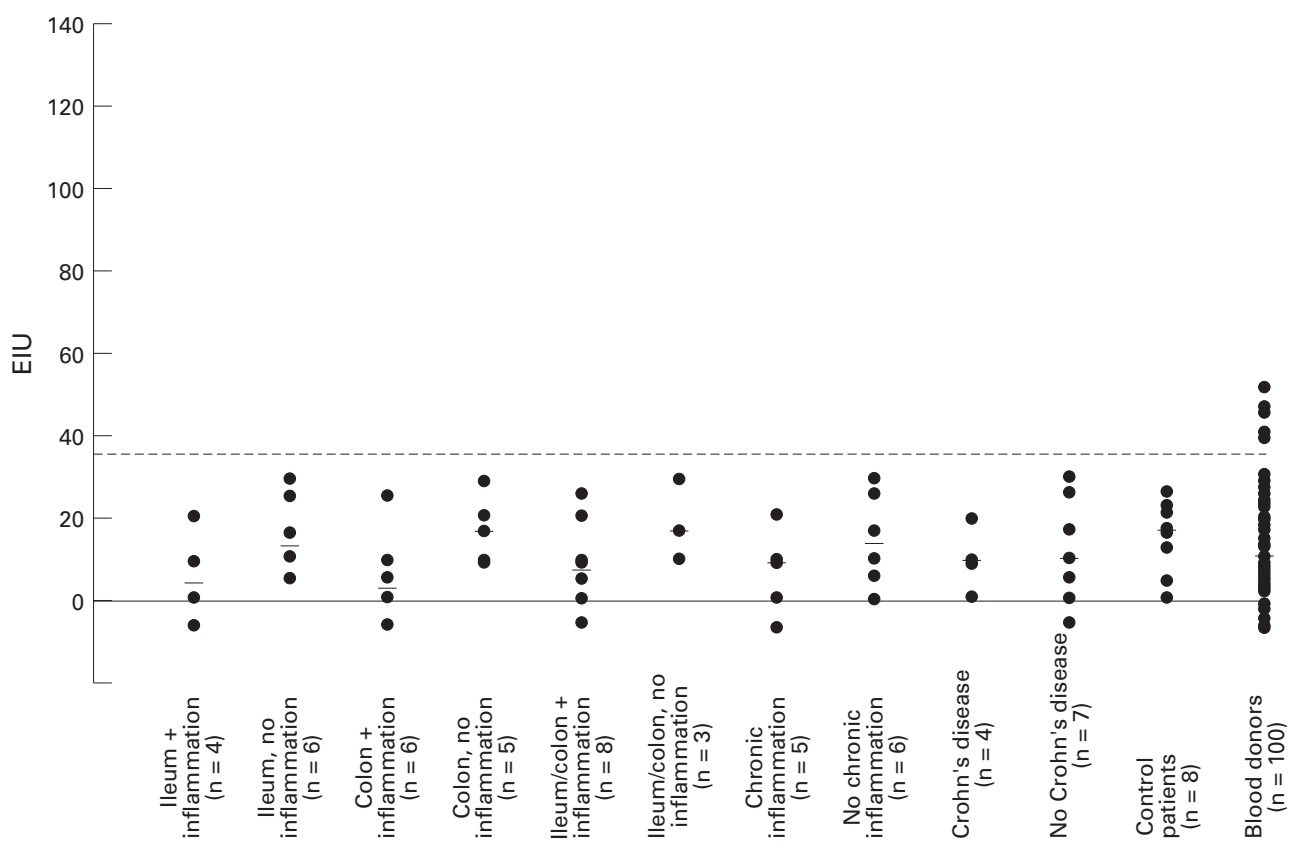

Figure 2 IgA class antibody concentrations to Klebsiella pneumoniae in serum samples of patients with peripheral type of ankylosing spondylitis, grouped according to ileocolonoscopic findings. Results for the control patients with other rheumatic diseases and healthy controls are also shown. The dashed line shows the antibody value for mean (2 SD) of the healthy blood donors. EIU, enzyme immunoassay unit. Median values for each subgroup have been marked with horizontal lines.

$(\mathrm{p}<0.01)$, chronic inflammation $(\mathrm{p}<0.05)$ or inflammation in ileum or colon $(\mathrm{p}<0.05)$ had significantly lower antibody values to $E$ coli than blood donors.

\section{Discussion}

Our results show that the Klebsiella specific IgA class serum antibody concentrations are increased and associated with gut inflammation, but only in patients with pure axial AS. This is logical as Klebsiella bacteria and their structures may pass into circulation more easily and in larger amounts through the inflamed mucosa to stimulate systemic immune responses. Kpneumoniae shares short sequence with the major histocompatibility antigen HLA-B27, ${ }^{10}$ which is closely associated with AS. Such mimicking could lead to unwanted cross reactivity (autoimmunity) or ineffective clearance (inappropriate tolerance) and thus to changed immune responses ${ }^{10}$ and consequently to the persistence of bacterial structures in the body as shown to be the case in another HLAB27 associated disease, reactive arthritis. ${ }^{112}$ However, mechanisms determining specificity of this phenomenon (association of increased enterobacterial antibody values with inflammation in the gut) primarily to Klebsiella and only to the pure axial form of AS are unknown and hence further studies and with a larger number of patients are warranted.

These findings may provide further evidence for the role of $K$ pneumoniae in the pathogenesis of AS. However, many of the patients with pure axial AS with and without gut inflammation, as well as patients with peripheral AS did not have increased $K$ pneumoniae antibody values, which may be regarded as an evidence against the direct role of $K$ pneumoniae in the pathogenesis. The find- ing of increased antibody concentration to $E$ coli in patients with inflammation in colon may have been caused by the close similarity of certain antigens of these microbes. The significantly lower antibody concentrations against $E$ coli in patients with peripheral AS when compared with the blood donors is difficult to interpret, but this is another dissimilarity between axial and peripheral forms of AS. Furthermore, as suggested already in the $1900 \mathrm{~s}^{13}$ and as continuously discussed today, the aetiopathogenetic mechanisms in the axial and peripheral form of AS may be different.

We thank Erkki Nieminen, M Sc, for help with statistical analyses and Mrs Tiina Lähde for technical assistance. Our study was supported by the Academy of Finland, the Sigrid Jusélius Foundation, the Paulo Foundation, the Finnish Cultural Foundation, the Rheumatism Research Foundation, and the European Commission Biomed 2 programme.

1 Ebringer A. Ankylosing spondylitis is caused by Klebsiella. Rheum Dis Clin North Am 1992;18:105-21.

2 Mäki-Ikola $\mathrm{O}$, Lehtinen $\mathrm{K}$, Granfors $\mathrm{K}$, Vainionpää R, Toivanen P. Bacterial antibodies in ankylosing spondylitis. Clin Exp Immunol 1991;84:472-5.

3 Mäki-Ikola O, Nissilä M, Lehtinen K, Leirisalo-Repo M, Granfors K. IgA1 and IgA2 subclass antibodies against Klebsiella pneumoniae in the sera of patients with peripheral and axial types of ankylosing spondylitis. Ann Rheum Dis 1995;54:631-5.

4 Mäki-Ikola O, Nissilä M, Lehtinen K, Leirisalo-Repo M, Toivanen P, Granfors K. Antibodies to Klebsiella pneumoToivanen P, Granfors K. Antibodies to Klebsiella pneumo-
niae, Escherichia coli and Proteus mirabilis in the sera of niae, Escherichia coli and Proteus mirabilis in the sera of patients with axial and peripheral form of
spondylitis. Br J Rheumatol 1995;34:413-7.

5 Russell AS, Almazor ES. Ankylosing spondylitis is not caused by Klebsiella. Rheum Dis Clin North Am 1992;18:95-104.

6 Leirisalo-Repo M, Turunen U, Stenman S, Helenius P, Seppälä K. High frequency of silent inflammatory bowel disease in spondyloarthropathy. Arthritis Rheum 1994; 37:23-31

7 Mielants H, Veys EM. The gut in the spondyloarthropathies. J Rheumatol 1990:17:7-10.

8 Smith MD, Gibson RA, Brooks PM. Abnormal bowel permeability in ankylosing spondylitis and rheumatoid

9 Kirwan J, Edwards A, Huitfeldt B, Thompson P, Currey H. The course of established ankylosing spondylitis and the effects of sulphasalazine over 3 years. $\mathrm{Br} \mathrm{J} \mathrm{Rheumatol}$ 1993;32:729-33. 
10 Scofield RH, Kurien B, Gross T, Warren WL, Harley JB. HLA-B27 binding of peptide from its own sequence and HLA-B27 binding of peptide from its own sequence and
similar peptides from bacteria: implications for spondysimilar peptides from bacteria: implicatio
loarthropathies. Lancet 1995;345:1542-4.

11 Mäki-Ikola O, Granfors K. Salmonella-triggered reactive arthritis. Lancet 1992;339:1096-8.
12 Granfors K, Jalkanen S, Lindberg AA, et al. Salmonella lipopolysaccharide in synovial cells from patients with lipopolysaccharide in synovial cells from

13 Sivén VO. Zur Kenntniss der sogen, chronisch ankylosirenden Entzündung der Wirbelsäule. Z Klin Med
rendi1903;49:343-76.

\section{Unusual but memorable}

\section{Series editor: Gary D Wright}

A 40 year old black women presented with pronounced soft tissue swelling of several fingers and toes, with tenderness and restriction of involved interphalangeal joints. A few patches of indurated depigmented skin were also noted. Radiographs revealed gross soft tissue swelling with deforming erosion and resorption of phalanges (figure).

Osseous involvement in chronic sarcoidosis occurs in about $5 \%$ of all patients. The most characteristic clinical picture is dactylitis resulting from granulomatous cyst formation in the phalanges where it may be the presenting feature of the

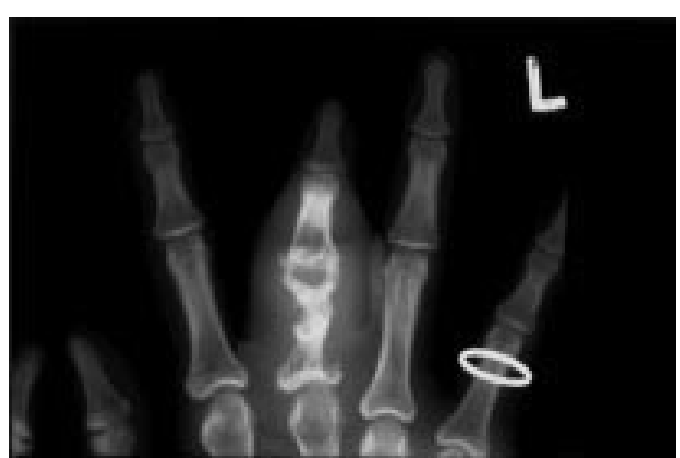
disease particularly in black patients. ${ }^{1}$

Numerous radiographic features have been described including expanded phalanges with thin cortical bone and cyst-like spaces, round or oval punched out areas, and fine lattice-like configuration. Periostial reaction is rare. In severe cases, as in this patient, affected phalanges may be fragmented and resorbed with "telescoping" of the digit. Severe soft tissue swelling may result from granulomatous change in the tendon sheath and joint synovium adjacent to affected bones. Joint destruction and collapse may follow local extension of osseous disease.

1 Leibowitz MR, Essop AR, Schamroth CL, Blumsohn D, Smith EH. Sarcoid dactylitis in black South African patients. Semin Arthritis Rheum 1985;14:232-7.

Contributors: GARY D WRIGHT, MICHAEL DOHERTY. City Hospital, Nottingham, NG5 1PB, United Kingdom. 